\title{
Determinants of 2009 A/H1N1 Influenza Vaccination Among Pregnant Women in Hong Kong
}

\author{
Marie Tarrant $\cdot$ Kendra M. Wu • \\ Carol Yuet Sheung Yuen • Ka Lun Cheung • \\ Vincci Hiu Sze Chan
}

Published online: 2 February 2012

(c) The Author(s) 2012. This article is published with open access at Springerlink.com

\begin{abstract}
During the 2009-2010 A/H1N1 influenza pandemic, pregnant women infected with the virus experienced excess morbidity and mortality when compared with other groups. Once a vaccine was available, pregnant women were a priority group for vaccination. Only a few studies have reported on the uptake of 2009 A/H1N1 influenza vaccine among pregnant women during the pandemic and none were from Asia. The purpose of this study was to examine factors associated with 2009 A/H1N1 influenza vaccine uptake among pregnant women in Hong Kong. Using a multi-center, cross-sectional design, we recruited 549 postpartum women from four post-natal wards in Hong Kong over a 4-month period during the second wave of the A/H1N1 influenza pandemic in the winter and spring of 2010. Only $6.2 \%(\mathrm{n}=34)$ of participants had received the $2009 \mathrm{~A} / \mathrm{H} 1 \mathrm{~N} 1$ influenza vaccine and $4.9 \%(\mathrm{n}=27)$ had received the seasonal influenza vaccine. The most common reasons for not receiving the
\end{abstract}

M. Tarrant $(\bowtie) \cdot$ C. Y. S. Yuen · K. L. Cheung · V. H. S. Chan

School of Nursing, Li Ka Shing Faculty of Medicine, 4/F,

William M. W. Mong Block, 21 Sassoon Road, Pokfulam,

Hong Kong

e-mail: tarrantm@hku.hk

C. Y. S. Yuen

e-mail: carol_iou@hotmail.com

K. L. Cheung

e-mail: hawthornn@hotmail.com

V. H. S. Chan

e-mail: chanvin@hku.hk

K. M. Wu

School of Public Health, Li Ka Shing Faculty of Medicine,

21 Sassoon Road, Pokfulam, Hong Kong

e-mail: kendrawu@hku.hk
2009 A/H1N1 vaccine were fear of causing harm to themselves or their fetus. A high knowledge level $(\mathrm{OR}=19.06 ; 95 \%$ CI $5.55,65.48)$, more positive attitudes $(\mathrm{OR}=3.52 ; 95 \%$ CI $1.37,9.07)$, and having a family member who had the $2009 \mathrm{~A} / \mathrm{H} 1 \mathrm{~N} 1$ influenza vaccine $(\mathrm{OR}=7.69 ; 95 \%$ CI 2.92, 20.19) were independently and positively associated with vaccination. Study results show an unacceptably low uptake of the pandemic $A / H 1 N 1$ influenza vaccine among pregnant women in Hong Kong. Interventions to increase influenza vaccine knowledge and uptake among this group should be a priority for future pandemic planning and seasonal vaccination campaigns.

Keywords H1N1 Pregnancy - Influenza ·

Vaccination · Hong Kong

\section{Background}

Pregnant women who contract influenza are at a greater risk of being hospitalized [1,2], of being hospitalized for longer duration [3] and of pregnancy complications such as pre-term labor, fetal distress, and cesarean section [3, 4]. In addition, the risk of hospitalization for cardiopulmonary conditions increases progressively as the pregnancy advances [2, 3, 5]. When compared with their non-pregnant peers, the risk of hospital admission among pregnant women is approximately 50\% higher from weeks 14-20 and almost fivefold higher in weeks $37-42$, resulting in approximately 2.5 hospitalizations per 1,000 third trimester women attributable to influenza infection [5]. This level of risk is equal to or higher than that of persons aged 65-69 years [6] or those with high-risk chronic diseases, such as cardiac and renal disease, diabetes mellitus, and immune suppression [5]. 
In early 2009, a novel strain of influenza A/H1N1 emerged in Mexico and spread rapidly to almost all other countries around the globe [7]. In Hong Kong, the first case of pandemic A/H1N1 influenza was identified on May 1, 2009 and the disease spread among the population despite early containment measures [8]. Although the majority of 2009 A/H1N1 influenza infections produced only mild symptoms [9], excess morbidity and mortality were observed in pregnant women during the pandemic $[10,11]$. In the United States (US), a greater proportion of pregnant women infected with 2009 A/H1N1 influenza required hospitalization when compared with the general population (32.4.\% vs. $4.2 \%)$ and $5-13 \%$ of all $\mathrm{A} / \mathrm{H} 1 \mathrm{~N} 1$ influenza deaths in the early part of the pandemic were among pregnant women [10, 12]. In France, almost 50\% of pregnant women infected with 2009 A/H1N1 influenza required hospitalization and $13 \%$ required admission to an intensive care unit (ICU) [13]. Overall, pregnant women were five times more likely than other infected persons to be admitted to ICU [14]. In the United Kingdom, Australia and New Zealand, $10 \%$ of pregnant women infected with 2009 A/H1N1 influenza admitted to an ICU died, over $10 \%$ experienced a pregnancy loss, and over $50 \%$ had a pre-term delivery [15]. In another study of 64 pregnant women with 2009 A/H1N1 influenza in Australia and New Zealand who were admitted to an ICU, none had been vaccinated [16]. In Asia, the outcomes for pregnant women infected with 2009 A/H1N1 influenza were more favorable [17, 18]. In Hong Kong, 87 pregnant women with 2009 A/H1N1 infection were admitted to public hospitals from the beginning of the pandemic up until May 2010, only one required mechanical ventilation and none died [19].

While some researchers have questioned both the necessity and safety of influenza vaccine during pregnancy [20, 21], Hong Kong [22] and many other countries [23-25], recommend seasonal influenza vaccines for all pregnant women during influenza season, regardless of their gestational age, to reduce the cardiopulmonary complications and hospitalizations associated with influenza infection $[22,26]$. During the A/H1N1 influenza pandemic, groups that were experiencing the greatest morbidity and mortality from influenza, such as pregnant women, were again a priority group for vaccination [25]. In Hong Kong, the vaccine became available in December 2009 and pregnant women were prioritized to receive the first available doses [27]. A previous study on uptake of prepandemic seasonal influenza vaccine among pregnant women in Hong Kong showed that only $3.9 \%$ had been vaccinated during pregnancy [28]. The purpose of this study was to examine factors associated with 2009 A/H1N1 influenza vaccine uptake among pregnant women in Hong Kong.

\section{Methods}

Design and Participants

This study used a multi-center, cross-sectional design. New mothers admitted to the post-natal obstetric units of four geographically and socio-economically distributed public hospitals in Hong Kong (two hospitals from Hong Kong Island and two from the Kowloon Peninsula) were recruited into the study in the immediate post-partum period. Each hospital has more than 300 deliveries per month. Participants were recruited during the second wave of the A/H1N1 influenza pandemic, from February to June 2010. The following criteria were used for selection of the study participants: (1) 18 years of age or older, (2) Cantonese speaking, (3) singleton pregnancies, (4) Hong Kong residents, and (5) no serious medical or obstetrical complications (i.e., infant born at $<37$ weeks gestation, a birth weight $<2,500 \mathrm{~g}$, admission to the neonatal intensive care unit, congenital anomalies, or birth defects). All eligible patients who were on the postnatal ward at the time of data collection were asked if they would like to participate.

\section{Study Instruments}

Participants were recruited during their immediate postpartum stay and were asked to complete a questionnaire that consisted of four sections. The first section consisted of questions about their 2009 A/H1N1 influenza vaccination status, the vaccination status of family members, provider recommendations regarding vaccination, reasons for not being vaccinated and respiratory infections in the participant or family members. The second section asked questions about the participants' health status before and during the pregnancy. The third section consisted of a 23 -item scale that measured participants' knowledge (16 items) and attitudes (7 items) toward pandemic A/H1N1 influenza, the $\mathrm{A} / \mathrm{H} 1 \mathrm{H} 1$ influenza vaccine, and $\mathrm{A} / \mathrm{H} 1 \mathrm{~N} 1$ influenza infection during pregnancy. Participants' responses were measured on a 4-point Likert scale (strongly disagree, disagree somewhat, agree somewhat, strongly agree). Instead of a 5-point scale, a 4-point scale was chosen to mitigate the risk of obtaining a large proportion of neutral responses, which has been observed in other studies in this population [29]. The final section consisted of baseline demographic data including age, education, income, and employment status. The questionnaire was adapted from a previously used survey instrument designed by Tong et al. [30] and was used with the permission of the researchers. Before use, the study instrument was translated into Chinese (Cantonese) by an expert translator. To ensure accuracy of the translation, back translation of the Chinese version of the instrument into English was also performed by a 
different translator as per established guidelines [31, 32]. The Chinese version of the questionnaire was reviewed by two Chinese speaking researchers to ensure that the concepts would be clearly understood by Hong Kong mothers and that the wording was culturally appropriate.

\section{Data Analysis}

The outcome variable was $2009 \mathrm{~A} / \mathrm{H} 1 \mathrm{~N} 1$ influenza vaccination status. Knowledge and attitude items were recoded into two categories to reflect either correct or incorrect responses in the case of knowledge items or either positive or negative responses in the case of attitude items. For both scales, a total score was calculated by summing all scale items. Negatively worded items were reverse coded so that higher scores reflected better knowledge levels and more positive attitudes. To facilitate further analysis of the effect of knowledge and attitudes on the study outcome, we collapsed total scores into categories based on the response distribution. Knowledge scores were categorized as low (score 0-5), medium (score 6-10) or high (score 11-16) and attitude scores were categorized as negative (score 0-2) or positive (score 3-7). Chi-square statistics and Student's $t$ tests were performed for the bivariate analyses. A multiple logistic regression analysis was performed to estimate the independent contribution, with corresponding odds ratios (ORs), of study variables to vaccination status. All variables with a significance level of $P<.05$ in the bivariate analysis were entered into the model and odds ratios with $95 \%$ confidence intervals were calculated. The Hosmer-Lemeshow test [33] was used to assess the fit of the logistic regression model and variance inflation factor (VIF) was used to assess for multicollinearity [34]. The 0.05 level of significance was used throughout the statistical analysis. All data analysis was conducted using Stata version 11.1 statistical software (Stata Corp, College Station, Tx) [35].

Before data collection, ethical approval for the study was obtained from the Institutional Review Board of the $\mathrm{Li}$ Ka-Shing Faculty of Medicine, University of Hong Kong and from all of the participating institutions. Informed written consent was obtained from all participants.

\section{Results}

We recruited 549 participants from the four study sites (Site $\mathrm{A}=159$; Site $\mathrm{B}=141$; Site $\mathrm{C}=140$; Site $\mathrm{D}=109$ ). Among the 549 participants, $6.2 \% \quad(\mathrm{n}=34)$ reported receiving the $2009 \mathrm{~A} / \mathrm{H} 1 \mathrm{~N} 1$ influenza vaccine, $4.9 \%$ $(\mathrm{n}=27)$ reported receiving the seasonal influenza vaccine, and $2.2 \%(\mathrm{n}=12)$ had received both vaccines. Overall,
$8.9 \%$ received at least one of the vaccines and $91.1 \%$ of participants had not received any influenza vaccine during their pregnancy. The proportion of participants receiving the $2009 \mathrm{~A} / \mathrm{H} 1 \mathrm{~N} 1$ vaccine varied slightly between hospitals (Site A: $15 / 144=9.4 \%$; Site B: $7 / 141=5.0 \%$; Site C: $5 / 135=3.6 \%$; Site D: $7 / 102=6.4 \%$ ).

The characteristics of the study participants according to vaccination status are presented in Table 1 . There were few demographic differences between vaccinated and unvaccinated participants. In general, vaccinated mothers had a higher education level and higher income but the differences were not statistically significant. $25.9 \%(\mathrm{n}=142)$ of participants reported that they had experienced a respiratory infection during pregnancy, although this was also not significantly associated with vaccination status. Vaccinated participants were significantly more likely to have received the seasonal influenza vaccine previously and to have a family member who was also vaccinated against A/H1N1. The two most common reasons for not being vaccinated were fear of harm to the participant or the fetus (Table 2).

A total knowledge score ranging from 0 to 16 was calculated based on the responses to the knowledge items. The mean score was $6.44(\mathrm{SD}=2.85)$, indicating overall low knowledge levels. Mean knowledge scores were significantly higher among the vaccinated group (10.3; SD = 3.5) when compared with the unvaccinated group (6.2; $\mathrm{SD}=2.6)(P<.001)$. A majority of participants agreed that $2009 \mathrm{~A} / \mathrm{H} 1 \mathrm{~N} 1$ influenza was a serious disease that often resulted in hospitalization (Table 3). Nevertheless, vaccinated participants were significantly more likely to agree that $2009 \mathrm{~A} / \mathrm{H} 1 \mathrm{~N} 1$ influenza was more serious for pregnant women and to believe that their fetus could benefit from maternal $2009 \mathrm{~A} / \mathrm{H} 1 \mathrm{~N} 1$ vaccination while in utero and in the first 6 months of life. Less than one-third of all participants knew that the 2009 A/H1N1 influenza vaccine was recommended for pregnant women in Hong Kong, with vaccinated participants significantly more likely to know this. In addition, vaccinated participants were significantly more likely to believe that 2009 A/H1N1 influenza vaccine was safe at all stages of pregnancy. Overall, influenza vaccination rates were $1.8 \%(4 / 222)$ among participants with low knowledge scores, 3.7\% (10/ 274) among participants with medium knowledge scores, and $37.7 \%$ (20/53) among participants with high knowledge scores $(P<.001)$.

A total attitude score ranging from 0 to 7 was calculated based on the responses to the attitude items. The mean attitude score for all participants was $2.3(\mathrm{SD}=1.49)$. As well, the mean attitude score was significantly higher among the vaccinated group (3.9; $\mathrm{SD}=1.5)$ when compared with the unvaccinated group $(2.2 ; \mathrm{SD}=1.4)$ $(P<.001)$. All participants were equally concerned about potential side effects and illness resulting from vaccination, 
Table 1 Characteristics of participants according to 2009 A/H1N1 influenza vaccination status

\begin{tabular}{lll}
\hline Demographic variable & $\begin{array}{l}\text { H1N1 influenza vaccine } \\
\text { uptake }\end{array}$ & \\
\cline { 2 - 3 } & No value \\
& $\mathrm{N}(\%)$ & $\mathrm{Nes}$ \\
$\mathrm{N}=515$ & $\mathrm{~N}(\%)$ \\
& & \\
\hline
\end{tabular}

\begin{tabular}{|c|c|c|c|}
\hline \multicolumn{4}{|l|}{ Age of mother } \\
\hline$\leq 24$ years & $36(7.0)$ & $6(17.7)$ & \multirow[t]{4}{*}{.12} \\
\hline $25-29$ years & $125(24.3)$ & $6(17.7)$ & \\
\hline $30-34$ years & $236(45.8)$ & $13(38.2)$ & \\
\hline$\geq 35$ years & $118(22.9)$ & $9(26.5)$ & \\
\hline \multicolumn{4}{|l|}{ Maternal education } \\
\hline Compulsory secondary & $264(51.3)$ & $15(44.1)$ & \multirow[t]{3}{*}{.14} \\
\hline Upper secondary & $103(20.0)$ & $4(11.8)$ & \\
\hline University degree or above & $148(28.7)$ & $15(44.1)$ & \\
\hline \multicolumn{4}{|l|}{ Family income $^{\dagger}$} \\
\hline Less than median income & $227(44.3)$ & $13(38.2)$ & \multirow[t]{2}{*}{.51} \\
\hline Median income or greater & $286(55.8)$ & $21(61.8)$ & \\
\hline \multicolumn{4}{|l|}{ Place of birth } \\
\hline Hong Kong & $346(67.2)$ & $23(67.7)$ & \multirow[t]{3}{*}{.95} \\
\hline Mainland China & $158(30.7)$ & $10(29.4)$ & \\
\hline Other & $11(2.1)$ & $1(2.9)$ & \\
\hline \multicolumn{4}{|c|}{ Length of residence in Hong Kong } \\
\hline$<10$ years & $72(14.0)$ & $4(11.8)$ & \multirow[t]{3}{*}{.85} \\
\hline 10 to $\geq 15$ years & $103(20.0)$ & $8(23.5)$ & \\
\hline Since birth & $340(66.0)$ & $22(64.7)$ & \\
\hline \multicolumn{4}{|l|}{ Breastfeeding infant } \\
\hline No & $82(15.9)$ & $3(8.8)$ & \multirow[t]{2}{*}{.27} \\
\hline Yes & $433(84.1)$ & $31(91.2)$ & \\
\hline \multicolumn{4}{|l|}{ Husband smokes } \\
\hline No & $350(68.4)$ & $24(70.6)$ & \multirow[t]{2}{*}{.75} \\
\hline Yes & $162(31.6)$ & $10(29.4)$ & \\
\hline \multicolumn{4}{|c|}{ Advised by $\mathrm{HCP}^{+}$to receive vaccine } \\
\hline No & $358(69.8)$ & $28(82.4)$ & \multirow[t]{2}{*}{.12} \\
\hline Yes & $155(30.2)$ & $6(17.7)$ & \\
\hline \multicolumn{4}{|c|}{ Received seasonal influenza vaccine before } \\
\hline No & $392(76.1)$ & $20(58.8)$ & \multirow[t]{2}{*}{.02} \\
\hline Yes & $123(23.9)$ & $14(41.2)$ & \\
\hline \multicolumn{4}{|c|}{ Family member received $\mathrm{A} / \mathrm{H} 1 \mathrm{~N} 1$ vaccine } \\
\hline No & $478(93.0)$ & $19(55.9)$ & \multirow[t]{2}{*}{$<.001$} \\
\hline Yes & $36(7.0)$ & $15(44.1)$ & \\
\hline \multicolumn{4}{|c|}{ Family member had A/H1N1 influenza } \\
\hline No & $505(98.1)$ & $32(94.1)$ & \multirow[t]{2}{*}{.13} \\
\hline Yes & $10(1.94)$ & $2(5.9)$ & \\
\hline \multicolumn{4}{|c|}{ Respiratory infection during pregnancy } \\
\hline No & $386(75.0)$ & $21(61.8)$ & \multirow[t]{2}{*}{.09} \\
\hline Yes & $129(25.1)$ & $13(38.2)$ & \\
\hline
\end{tabular}

Table 1 continued

\begin{tabular}{|c|c|c|c|}
\hline \multirow[t]{2}{*}{ Demographic variable } & \multicolumn{2}{|c|}{$\begin{array}{l}\text { H1N1 influenza vaccine } \\
\text { uptake }\end{array}$} & \multirow[t]{2}{*}{$P$ value } \\
\hline & $\begin{array}{l}\text { No } \\
\mathrm{N}(\%) \\
\mathrm{N}=515\end{array}$ & $\begin{array}{l}\text { Yes } \\
\mathrm{N}(\%) \\
\mathrm{N}=34\end{array}$ & \\
\hline \multicolumn{4}{|c|}{ Pre-existing chronic disease } \\
\hline No & $490(95.2)$ & $33(97.1)$ & .61 \\
\hline Yes & $25(4.9)$ & $1(2.9)$ & \\
\hline
\end{tabular}

though vaccinated participants were more likely to believe the $2009 \mathrm{~A} / \mathrm{H} 1 \mathrm{~N} 1$ influenza vaccine was effective in preventing influenza (Table 4). Unvaccinated participants were significantly more likely to agree that vaccines should not be taken during pregnancy and that the risk of vaccination was greater than the risk of $2009 \mathrm{~A} / \mathrm{H} 1 \mathrm{~N} 1$ influenza. Vaccination rates were $2.1 \%$ (7/327) among participants with negative attitudes and $12.2 \%(27 / 222)$ among participants with more positive attitudes $(P<.001)$.

Results of the logistic regression analysis identified having a family member vaccinated with 2009 A/H1N1 influenza vaccine $(\mathrm{OR}=7.69 ; 95 \%$ CI $2.92,20.19)$, high levels of knowledge $(\mathrm{OR}=19.06 ; 95 \%$ CI 5.55, 65.48) and more positive attitudes $(\mathrm{OR}=3.52 ; 95 \%$ CI 1.37 , 9.07) as factors independently and positively associated with vaccination (Table 5). The Hosmer-Lemeshow goodness-of-fit $\mathrm{chi}^{2}$ statistic for this model was 12.69 $(P=0.70)$, indicating a good fit for the data. VIF values showed no evidence of multicollinearity.

\section{Discussion}

In this study we examined uptake of the 2009 A/H1N1 influenza vaccine among pregnant women in Hong Kong during the second wave of the pandemic and identified factors associated with vaccination. Results of this study showed: (1) a low vaccination rate, (2) a lack of awareness of the recommendations for vaccination among unvaccinated participants, (3) a high level of concern among unvaccinated participants about the safety of the vaccine for both the mother and the fetus, (4) better knowledge and more positive attitudes among vaccinated participants, and (5) greater exposure to the $2009 \mathrm{~A} / \mathrm{H} 1 \mathrm{~N} 1$ influenza vaccine among vaccinated participants.

2009 A/H1N1 influenza vaccination rates in this study were similar to those reported among pregnant women in 
Table 2 Reasons for not receiving the 2009 A/H1N1 influenza vaccine

\begin{tabular}{lc}
\hline & $\mathrm{N}(\%)$ \\
\hline $\begin{array}{l}\text { 1. I was afraid that the vaccine would cause side effects } \\
\text { for my baby }\end{array}$ & $395(75.7)$ \\
2. I was afraid that the vaccine would cause side effects & $364(69.7)$ \\
for me & \\
3. I was afraid that the vaccine would hurt/I am scared of & $103(19.7)$ \\
needles & $75(14.4)$ \\
4. The vaccine is unnecessary during pregnancy & $53(10.2)$ \\
5. My doctor/nurse did not recommend the vaccine & $58(11.1)$ \\
6. I was not worried about being ill with influenza during & \\
pregnancy & $43(8.2)$ \\
7. Influenza is not a serious illness & $31(5.9)$ \\
8. My doctor/nurse did not discuss the vaccine with me & $21(4.0)$ \\
9. The vaccine is not beneficial in protecting or & \\
preventing influenza & $6(1.2)$ \\
10. I had previous side effects from the influenza vaccine & $18(3.5)$ \\
11. Other
\end{tabular}

Note: Participants could select more than one response

Australia (6.9\%) [36] and Turkey (8.9\%) [37] but substantially below those reported in France (22.7-37.1\%) [38, 39], the US (45.7-46.6\%) [40, 41], and Canada (72-76\%) $[42,43]$. The $2009 \mathrm{~A} / \mathrm{H} 1 \mathrm{~N} 1$ influenza vaccine uptake rate among pregnant women in Hong Kong was also similar to the uptake rate of 5\% among the Hong Kong general population [44] and the seasonal vaccine uptake rate of $3.9 \%$ among pregnant women in Hong Kong during the 2005/2006 influenza season [28]. Studies in other countries have also shown that seasonal influenza vaccination rates among pregnant women ranged from only $2-20 \%$ [2, 30, 45-49]. Although pregnant women were a priority group for vaccination and the local Department of Health actively encouraged high risk groups to receive the vaccination, the majority of participants remained unaware that they should be vaccinated. In addition, we collected our data during the second wave of the $\mathrm{A} / \mathrm{H} 1 \mathrm{~N} 1$ pandemic in the winter and spring of 2010. At this point, the more dire predictions about potential outcomes of a global influenza pandemic had not been realized and overall, the pandemic was considered to be mild [9]. In Hong Kong, the A/H1N1 pandemic peaked in September 2009 and there were far fewer infections in the second wave of the pandemic during the winter of 2009-2010 [50, 51]. This may have contributed to the low vaccination rate among pregnant women.

Influenza vaccine has been demonstrated to be safe for pregnant women in any trimester and the risks associated with influenza infection during pregnancy are substantial [49, 52-54]. In addition, research has shown that influenza vaccination during pregnancy can reduce hospitalizations among infants $<6$ months of age for influenza and influenza like illnesses by 45-63\% [55-57]. Despite this evidence, concerns about safety and side effects of influenza vaccine and possible birth defects resulting from vaccination continue to be the major reasons pregnant women remain reluctant to receive both the seasonal and H1N1 influenza vaccine during pregnancy $[26,30,40$, 58-62]. These findings suggest a sub-optimal response to public health campaigns to inform pregnant women about both the dangers of $2009 \mathrm{~A} / \mathrm{H} 1 \mathrm{~N} 1$ influenza during pregnancy and the benefits and safety of the 2009 A/H1N1 influenza vaccine. Participants in this study with higher knowledge levels, more positive attitudes and more exposure to the vaccine were substantially more likely to be vaccinated, indicating that greater education and promotion of the vaccine may increase uptake. Accordingly, the Centers for Disease Control and Prevention reported substantial increases in the uptake of both seasonal and 2009 $\mathrm{A} / \mathrm{H} 1 \mathrm{~N} 1$ influenza vaccines among pregnant women in the United States during the 2009-2010 influenza season after focused public health education efforts [40].

In Hong Kong, it is likely that the media also played a role in both the low uptake of vaccination and the beliefs about potential side effects of vaccination. During the pandemic, the local media prominently reported cases of pregnant women who experienced miscarriages and stillbirths after having received the 2009 A/H1N1 vaccine [63-65]. There were also several cases of Guillain-Barré Syndrome among men after 2009 A/H1N1 vaccination that received wide coverage in the English and Chinese press [66]. These events often occurred weeks after vaccination and in the case of two of the stillbirths, there were other pregnancy complications. Despite reassurances from health professionals that the events were unrelated to the vaccine and that pregnant women and other groups should continue to be vaccinated [67], the adverse events were invariably linked to the vaccine in various media reports and vaccination rates among pregnant women and other high-risk groups fell after these incidents $[44,66]$.

A major source of information for pregnant women is their health-care provider (HCP). However, fewer than $30 \%$ of participants in this study were actually advised by their HCP to have the vaccine. Other studies done in Hong Kong during the $\mathrm{A} / \mathrm{H} 1 \mathrm{~N} 1$ pandemic have documented HCPs reluctance to receive the influenza vaccine themselves $[68,69]$. Therefore, it is not surprising that they did not encourage pregnant women to be vaccinated. Many HCPs are reluctant to recommend the influenza vaccine to pregnant women because they are unaware of this recommendation, they underestimate the risk of influenza during pregnancy, they believe that the vaccine is not effective in preventing influenza, they have concerns about the safety and effectiveness of the vaccine during pregnancy or they do not think it is part of their responsibility [30, 46, 59, 70, 71]. 
Table 3 Relationship between 2009 A/H1N1 influenza knowledge and vaccination status

\begin{tabular}{|c|c|c|c|c|c|}
\hline \multirow[t]{4}{*}{ Knowledge statement } & \multicolumn{4}{|c|}{ H1N1 influenza vaccine uptake } & \multirow[t]{4}{*}{$P$ value } \\
\hline & \multirow{2}{*}{\multicolumn{2}{|c|}{$\begin{array}{l}\text { Not vaccinated } \\
\mathrm{N}=515\end{array}$}} & \multirow{2}{*}{\multicolumn{2}{|c|}{$\frac{\text { Vaccinated }}{\mathrm{N}=34}$}} & \\
\hline & & & & & \\
\hline & $\begin{array}{l}\text { Agree } \\
\mathrm{N}(\%)\end{array}$ & $\begin{array}{l}\text { Disagree } \\
\mathrm{N}(\%)\end{array}$ & $\begin{array}{l}\text { Agree } \\
\mathrm{N}(\%)\end{array}$ & $\begin{array}{l}\text { Disagree } \\
\mathrm{N}(\%)\end{array}$ & \\
\hline $\mathrm{H} 1 \mathrm{~N} 1$ influenza is highly contagious & $397(77.2)$ & $117(22.8)$ & $29(85.3)$ & $5(14.7)$ & .27 \\
\hline $\begin{array}{l}\text { H1N1 influenza can sometimes be serious enough that a person needs to be } \\
\text { admitted to the hospital }\end{array}$ & $501(97.9)$ & $11(2.2)$ & $34(100.0)$ & $0(0.0)$ & .39 \\
\hline $\begin{array}{l}\text { H1N1 influenza can cause a lot more illness in pregnant women than in non- } \\
\text { pregnant women }\end{array}$ & $222(43.1)$ & $293(56.9)$ & $23(67.7)$ & $11(32.4)$ & $<.01$ \\
\hline $\begin{array}{l}\text { Pregnant women are at a higher risk of developing secondary complications due to } \\
\text { H1N1 influenza }\end{array}$ & 400 (77.7) & $115(22.3)$ & $33(97.1)$ & $1(2.9)$ & $<.01$ \\
\hline $\begin{array}{l}\text { Pregnant women are more likely to be hospitalized for H1N1 influenza than non- } \\
\text { pregnant women }\end{array}$ & $308(60.3)$ & $203(39.7)$ & $26(76.5)$ & $8(23.5)$ & .06 \\
\hline My baby may benefit from maternal H1N1 influenza vaccination while in the womb & $56(10.9)$ & $459(89.1)$ & $17(51.5)$ & $16(48.5)$ & $<.001$ \\
\hline $\begin{array}{l}\text { H1N1 influenza vaccination during pregnancy can have a protective effect on my } \\
\text { baby during the first } 6 \text { months of life }\end{array}$ & $75(14.8)$ & $433(85.2)$ & $14(41.2)$ & $20(58.8)$ & $<.001$ \\
\hline $\begin{array}{l}\text { In Hong Kong, it is recommended that all pregnant women get the H1N1 influenza } \\
\text { vaccine }\end{array}$ & $133(25.8)$ & $382(74.2)$ & $19(55.9)$ & $15(44.1)$ & $<.001$ \\
\hline H1N1 influenza vaccination is safe in pregnancy & $46(9.0)$ & $467(91.0)$ & $18(54.6)$ & $15(45.5)$ & $<.001$ \\
\hline In pregnancy, H1N1 influenza vaccination is safe in the first trimester & $51(9.9)$ & $464(90.1)$ & $10(29.4)$ & $24(70.6)$ & $<.001$ \\
\hline In pregnancy, H1N1 influenza vaccination is safe in the second trimester & $65(12.7)$ & $448(87.3)$ & $20(60.6)$ & $13(39.4)$ & $<.001$ \\
\hline In pregnancy, H1N1 influenza vaccination is safe in the third trimester & $62(12.1)$ & $452(87.9)$ & $15(45.5)$ & $18(54.6)$ & $<.001$ \\
\hline H1N1 influenza vaccine during pregnancy may induce spontaneous abortion & $423(82.3)$ & $91(17.7)$ & $19(57.6)$ & $14(42.4)$ & $<.001$ \\
\hline H1N1 influenza vaccine during pregnancy may induce pre-term contractions & $300(58.7)$ & $211(41.3)$ & $9(27.3)$ & $24(72.7)$ & $<.001$ \\
\hline H1N1 influenza vaccine during pregnancy can cause birth defects & $257(50.4)$ & $253(49.6)$ & 7 (20.6) & $27(79.4)$ & .001 \\
\hline $\begin{array}{l}\text { My baby might get the flu in the womb if I get the H1N1 influenza vaccine during } \\
\text { pregnancy }\end{array}$ & 197 (38.6) & 314 (61.5) & 7 (20.6) & $27(79.4)$ & $<.05$ \\
\hline
\end{tabular}

Table 4 Relationship between 2009 A/H1N1 influenza attitudes and vaccination status

\begin{tabular}{|c|c|c|c|c|c|}
\hline \multirow[t]{4}{*}{ Attitude statement } & \multicolumn{4}{|c|}{ H1N1 influenza Vaccine } & \multirow[t]{4}{*}{$P$ value } \\
\hline & \multirow{2}{*}{\multicolumn{2}{|c|}{$\begin{array}{l}\text { Not vaccinated } \\
\mathrm{N}=515\end{array}$}} & \multirow{2}{*}{\multicolumn{2}{|c|}{$\begin{array}{l}\text { Vaccinated } \\
\mathrm{N}=34\end{array}$}} & \\
\hline & & & & & \\
\hline & $\begin{array}{l}\text { Agree } \\
\mathrm{N}(\%)\end{array}$ & $\begin{array}{l}\text { Disagree } \\
\mathrm{N}(\%)\end{array}$ & $\begin{array}{l}\text { Agree } \\
\mathrm{N}(\%)\end{array}$ & $\begin{array}{l}\text { Disagree } \\
\mathrm{N}(\%)\end{array}$ & \\
\hline H1N1 influenza vaccines are effective in protecting people and preventing illness & $254(50.0)$ & $254(50.0)$ & $31(91.2)$ & $3(8.8)$ & $<.001$ \\
\hline I am concerned about side effects from the H1N1 influenza vaccine & $493(95.9)$ & $21(4.1)$ & $32(94.1)$ & $2(5.9)$ & .61 \\
\hline H1N1 influenza vaccine can cause severe illness & $376(73.6)$ & $135(26.4)$ & $23(67.7)$ & $11(32.4)$ & .45 \\
\hline H1N1 influenza vaccine can cause a person to be sick with the flu & $165(32.4)$ & $345(67.7)$ & $10(30.3)$ & $23(69.7)$ & .81 \\
\hline For healthy people, H1N1 influenza vaccine should be avoided & $382(74.5)$ & $131(25.5)$ & $18(52.9)$ & $16(47.1)$ & $<.01$ \\
\hline I think health care workers should be vaccinated against H1N1 influenza & $335(65.3)$ & $178(34.7)$ & $30(88.2)$ & $4(11.8)$ & $<.01$ \\
\hline $\begin{array}{l}\text { For pregnant women, the risk of the H1N1 influenza vaccination is greater than the } \\
\text { risk of getting influenza }\end{array}$ & $372(72.4)$ & $142(27.6)$ & $9(26.5)$ & $25(73.5)$ & $<.001$ \\
\hline All vaccines should be avoided during pregnancy & $406(78.8)$ & $109(21.2)$ & $10(29.4)$ & $24(70.6)$ & $<.001$ \\
\hline
\end{tabular}

Although a recommendation from a HCP was not associated with vaccination status in this study, other studies have shown that such recommendations were positively associated with influenza vaccine uptake among pregnant women [30, 40, 41, 61, 70]. With a novel virus, and especially when there is misinformation and hysteria being 
Table 5 Logistic regression analysis of the predictors of 2009 $\mathrm{A} / \mathrm{H} 1 \mathrm{~N} 1$ influenza vaccination

\begin{tabular}{|c|c|c|}
\hline & Adjusted OR (95\% CI) & $P$ value \\
\hline \multicolumn{3}{|c|}{ Received seasonal influenza vaccine before } \\
\hline No & 1 & \\
\hline Yes & $1.30(0.52,3.21)$ & 0.56 \\
\hline \multicolumn{3}{|c|}{ Family member received $\mathrm{A} / \mathrm{H} 1 \mathrm{~N} 1$ influenza vaccine } \\
\hline No & 1 & \\
\hline Yes & $7.69(2.92,20.19)$ & $<0.001$ \\
\hline \multicolumn{3}{|c|}{ Knowledge scores } \\
\hline Low & 1 & \\
\hline Medium & $1.40(0.41,4.77)$ & 0.59 \\
\hline High & $19.06(5.55,65.48)$ & $<0.001$ \\
\hline \multicolumn{3}{|c|}{ Attitude scores } \\
\hline Low & 1 & \\
\hline High & $3.52(1.37,9.07)$ & $<0.01$ \\
\hline
\end{tabular}

generated by the media, the role of the HCP in providing factual information and reassurance to pregnant women is more important because of uncertainty about the vaccine and the potential consequences [40]. In addition, publiclyfunded antenatal clinics in Hong Kong do not provide onsite vaccination, a situation that is similar to other countries [30]. Therefore, even if pregnant women are advised to get the vaccine, they have to go elsewhere to be vaccinated and thus may be less likely to seek out the vaccine. Offering and providing the influenza vaccine in the antenatal clinic setting has been shown to substantially increase vaccination uptake rates [72].

Participants in this study with a family member who had received the $2009 \mathrm{~A} / \mathrm{H} 1 \mathrm{~N} 1$ influenza vaccine were substantially more likely to be vaccinated. Exposure to vaccinated persons may help to decrease the perception of risk from vaccination. In addition, if one family member requires vaccination, especially if it is medically indicated, HCPs may be more likely to recommend vaccination to all family members. Similar to findings from other studies [39, 73], participants who had pre-existing co-morbid conditions were no more likely to receive the vaccine than those without preexisting conditions. Again, this may be due to lack of awareness of the recommendation for vaccination and/or the failure of health professionals to advise pregnant women with underlying chronic diseases to receive the vaccine.

\section{Strengths and Limitations}

This study is one of a number of studies to report on the actual uptake of 2009 A/H1N1 influenza vaccine among pregnant women during the 2009-2010 A/H1N1 pandemic $[36,37,39,40,42,43]$, but to our knowledge the first in
Asia. We recruited our sample from four geographically and socio-economically disparate hospitals across Hong Kong. As such, it provides a baseline for further research and can help to inform public health education and promotion programmes concerning influenza vaccine for pregnant women. Since we recruited new mothers in the immediate post-partum period, we measured actual uptake of vaccination during pregnancy and not just simply the intention to be vaccinated [74], which has been demonstrated to be an unreliable indicator of actual vaccination $[44,75]$. This study however, has several limitations. First, although we recruited participants from four hospitals, the sample was not population based and no data were collected from participants who refused to participate. Also, we do not know what proportion of eligible mothers chose not to participate. Second, our sample participated voluntarily and therefore, we cannot rule out the possibility that participants who had been vaccinated and had higher knowledge of 2009 A/H1N1 influenza were more likely to participate. Hence, if anything, the study results likely overestimate the uptake of 2009 A/H1N1 influenza vaccine among pregnant women in Hong Kong. Third, the low number of respondents who were actually vaccinated limited the statistical power of the study and thus our ability to identify factors significantly associated with vaccination uptake. In addition, researchers have pointed out that the use of logistic regression with samples that have highly skewed outcomes, such as what was found in this study, may result in overestimation of the odds ratios [76]. Thus, further research with a larger population-based sample is necessary to corroborate the study findings and to provide further insight into factors affecting influenza vaccine uptake.

\section{Conclusions}

Poor uptake of 2009 A/H1N1 influenza vaccination among pregnant women in Hong Kong was related to low knowledge levels, poor attitudes, and fear of vaccine side effects for the mother and baby. Increasing knowledge and awareness about the benefits of influenza vaccination for both the mother and the baby may increase uptake rates of both pandemic and seasonal influenza vaccine. Improving education for obstetric health-care providers, encouraging them to recommend vaccination for pregnant women and on-site provision of influenza vaccine in antenatal clinics could also improve vaccination rates. Finally, it is also important to further explore the influence of both HCPs and the media in pregnant women's decision making regarding influenza vaccine.

Acknowledgments This study was supported by a grant from the University of Hong Kong Small Project Funding (Grant: \#10400656). 
Open Access This article is distributed under the terms of the Creative Commons Attribution Noncommercial License which permits any noncommercial use, distribution, and reproduction in any medium, provided the original author(s) and source are credited.

\section{References}

1. Cox, S., Posner, S. F., McPheeters, M., Jamieson, D. J., Kourtis, A. P., \& Meikle, S. (2006). Influenza and pregnant women: Hospitalization burden, United States, 1998-2002. Journal of Women's Health, 15(8), 891-893.

2. Dodds, L., McNeil, S. A., Fell, D. B., Allen, V. M., Coombs, A., Scott, J., et al. (2007). Impact of influenza exposure on rates of hospital admissions and physician visits because of respiratory illness among pregnant women. CMAJ, 176(4), 463-468.

3. Cox, S., Posner, S. F., McPheeters, M., Jamieson, D. J., Kourtis, A. P., \& Meikle, S. (2006). Hospitalizations with respiratory illness among pregnant women during influenza season. Obstetrics and Gynecology, 107(6), 1315-1322.

4. Irving, W. L., James, D. K., Stephenson, T., Laing, P., Jameson, C., Oxford, J. S., et al. (2000). Influenza virus infection in the second and third trimesters of pregnancy: A clinical and seroepidemiological study. BJOG, 107(10), 1282-1289.

5. Neuzil, K. M., Reed, G. W., Mitchel, E. F., Simonsen, L., \& Griffin, M. R. (1998). Impact of influenza on acute cardiopulmonary hospitalizations in pregnant women. American Journal of Epidemiology, 148(11), 1094-1102.

6. Schanzer, D. L., Langley, J. M., \& Tam, T. W. S. (2007). Influenza-attributed hospitalization rates among pregnant women in Canada 1994-2000. Journal of Obstetrics and Gynaecology Canada, 29(8), 622-629.

7. Zarocostas, J. (2009). World Health Organization declares A (H1N1) influenza pandemic. BMJ, 338, b2425.

8. Centre for health protection. (2009). SFH on human swine flu. Hong Kong: Author. Accessed 2011 October 12. Available from: http://www.chp.gov.hk/en/content/116/16787.html.

9. Leung, G. M., \& Nicoll, A. (2010). Reflections on pandemic (H1N1) 2009 and the international response. PLoS Medicine, 7(10).

10. Jamieson, D. J., Honein, M. A., Rasmussen, S. A., Williams, J. L., Swerdlow, D. L., Biggerstaff, M. S., et al. (2009). H1N1 2009 influenza virus infection during pregnancy in the USA. Lancet, 374(9688), 451-458.

11. Centers for disease control and prevention. (2009). Pregnant women and novel influenza A (H1N1) virus: Considerations for clinicians. Atlanta, GA: Author. [updated July 27, 2009; Accessed 2011 May 24]; Available from: http://www.cdc.gov/h1n1flu/ clinician_pregnant.html.

12. Siston, A. M., Rasmussen, S. A., Honein, M. A., Fry, A. M., Seib, K., Callaghan, W. M., et al. (2010). Pandemic 2009 influenza $\mathrm{A}(\mathrm{H} 1 \mathrm{~N} 1)$ virus illness among pregnant women in the United States. JAMA, 303(15), 1517-1525.

13. Dubar, G., Azria, E., Tesnière, A., Dupont, H., Le Ray, C., Baugnon, T., et al. (2010). For the French Registry on 2009 A/H1N1v during pregnancy. French experience of 2009 A/H1N1v influenza in pregnant women. PLoS One, 5(10), e13112.

14. Hanslik, T., Boelle, P.-Y., \& Flahault, A. (2010). Preliminary estimation of risk factors for admission to intensive care units and for death in patients infected with A(H1N1)2009 influenza virus, France, 2009-2010. PLoS Current, 2, RRN1150.

15. Knight, M., Pierce, M., Seppelt, I., Kurinczuk, J. J., Spark, P., Brocklehurst, P., et al. (2011). Critical illness with AH1N1v influenza in pregnancy: A comparison of two population-based cohorts. BJOG, 118(2), 232-239.
16. Anzic Influenza Investigators and Australasian Maternity Outcomes Surveillance System. (2009). A/H1N1 influenza in pregnant and postpartum women: Population based cohort study. BMJ, 2010(340), c1279.

17. Lim, M. L., Chong, C. Y., Tee, W. S. N., Lim, W. Y., \& Chee, J. J. (2010). Influenza A/H1N1 (2009) infection in pregnancy-an Asian perspective. BJOG, 117(5), 551-556.

18. Lim, M. L., Lim, W. Y., Tee, N. W. S., Lim, S. H., \& Chee, J. J. (2010). Obstetric outcomes of influenza A H1N1 (2009) infection in pregnancy-experience of a Singapore tertiary hospital. Annals of the Academy of Medicine, Singapore, 39(4), 295-298.

19. Hospital Authority. (2010). Pandemic H1N1 influenza admissions to public hospitals in Hong Kong (unpublished data). Hong Kong.

20. Ayoub, D. M., \& Yazbak, F. E. (2008). A closer look at influenza vaccination during pregnancy. Lancet Infectious Diseases, 8(11), 660-661.

21. Skowronski, D. M., \& De Serres, G. (2009). Is routine influenza immunization warranted in early pregnancy? Vaccine, 27(35), 4754-4770.

22. Scientific Committee on Vaccine Preventable Diseases. (2010). Recommendations on influenza vaccination for the 2010/11 season. Hong Kong: Centre for Health Protection.

23. National Advisory Committee on Immunization (NACI). (2011). Statement on seasonal influenza vaccine for 2011-2012. Canada Communicable Disease Report, 37(ACS-5), 1-55.

24. National Health and Medical Research Council. (2008). The Australian immunisation handbook (9th ed., pp. 1-413). Australian Government Department of Health and Ageing.

25. Centers for Disease Control and Prevention. (2011). Prevention and control of influenza with vaccines: Recommendations of the Advisory Committee on Immunization Practices (ACIP), 2011. MMWR Morbidity and Mortality Weekly Report, 60(33), $1128-1132$.

26. Naleway, A. L., Smith, W. J., \& Mullooly, J. P. (2006). Delivering influenza vaccine to pregnant women. Epidemiologic Reviews, 28(1), 47-53.

27. Fielding, R. (2010). Pandemic influenza A/H1N1 (pH1N1) in Hong Kong: Anatomy of a response. NTS Working Paper Series No. 3. Singapore: RSIS Centre for Non-Traditional Security (NTS) Studies.

28. Lau, J. T., Cai, Y., Tsui, H. Y., \& Choi, K. C. (2010). Prevalence of influenza vaccination and associated factors among pregnant women in Hong Kong. Vaccine, 28(33), 5389-5397.

29. Lee, J. W., Jones, P. S., Mineyama, Y., \& Zhang, X. E. (2002). Cultural differences in responses to a Likert scale. Research in Nursing and Health, 25(4), 295-306.

30. Tong, A., Biringer, A., Ofner-Agostini, M., Upshur, R., \& McGeer, A. (2008). A cross-sectional study of maternity care providers' and women's knowledge, attitudes, and behaviours towards influenza vaccination during pregnancy. Journal of Obstetrics and Gynaecology Canada, 30(5), 404-410.

31. Brislin, R. W. (1986). The wording and translation of research instruments. In W. J. Loner \& J. W. Berry (Eds.), Field methods in cross-cultural research (pp. 137-164). Beverly Hills, CA: Sage.

32. Chapman, D. W., \& Carter, J. F. (1979). Translation procedures for the cross-cultural use of measurement. Educational Evaluation and Policy Analysis, 1(3), 71-76.

33. Hosmer, D. W., Hosmer, T., Le Cessie, S., \& Lemeshow, S. (1997). A comparison of goodness-of-fit tests for the logistic regression model. Statistics in Medicine, 16(9), 965-980.

34. Hair, J. F. (2010). Multivariate data analysis (7th ed.). Upper Saddle River, NJ: Prentice Hall.

35. StataCorp. (2010). Stata statistical software: Release 11.1. College Station, TX: StataCorp LP. 
36. White, S. W., Petersen, R. W., \& Quinlivan, J. A. (2010). Pandemic (H1N1) 2009 influenza vaccine uptake in pregnant women entering the 2010 influenza season in Western Australia. Medical Journal of Australia, 193(7), 405-407.

37. Ozer, A., Arikan, D. C., Kirecci, E., \& Ekerbicer, H. C. (2010). Status of pandemic influenza vaccination and factors affecting it in pregnant women in Kahramanmaras, an eastern Mediterranean city of Turkey. PLoS One, 5(12), e14177.

38. Bone, A., Guthmann, J.-P., Nicolau, J., \& Levy-Bruhl, D. (2010). Population and risk group uptake of H1N1 influenza vaccine in mainland France 2009-2010: Results of a national vaccination campaign. Vaccine, 28(51), 8157-8161.

39. Freund, R., Le Ray, C., Charlier, C., Avenell, C., Truster, V., Treluyer, J. M., et al. (2011). Determinants of non-vaccination against pandemic $2009 \mathrm{H} 1 \mathrm{~N} 1$ influenza in pregnant women: A prospective cohort study. PLOS ONE, 6(6), e20900.

40. Centers for Disease Control and Prevention. (2010). Seasonal influenza and 2009 H1N1 influenza vaccination coverage among pregnant women-10 states, 2009-10 influenza season. MMWR Morbidity and Mortality Weekly Report, 59(47), 1541-1545.

41. Ding, H., Santibanez, T. A., Jamieson, D. J., Weinbaum, C. M., Euler, G. L., Grohskopf, L. A., et al. (2011). Influenza vaccination coverage among pregnant women-National 2009 H1N1 Flu Survey (NHFS). American Journal of Obstetrics and Gynecology, 204(6 Suppl 1), S96-S106.

42. Fabry, P., Gagneur, A., \& Pasquier, J. C. (2011). Determinants of A (H1N1) vaccination: Cross-sectional study in a population of pregnant women in Quebec. Vaccine, 29(9), 1824-1829.

43. Gracie, S., Metcalfe, A., Dolan, S. M., Kehler, H., Siever, J., \& Tough, S. (2011). Utilization of the $2009 \mathrm{H} 1 \mathrm{~N} 1$ vaccine by pregnant women in a pandemic year. Journal of Obstetrics and Gynaecology Canada, 33(2), 127-133.

44. Liao, Q., Cowling, B. J., Lam, W. W., \& Fielding, R. (2011). Factors affecting intention to receive and self-reported receipt of 2009 pandemic (H1N1) vaccine in Hong Kong: A longitudinal study. PLoS One, 6(3), e17713.

45. Black, S. B., Shinefield, H. R., France, E. K., Fireman, B. H., Platt, S. T., \& Shay, D. (2004). Effectiveness of influenza vaccine during pregnancy in preventing hospitalizations and outpatient visits for respiratory illness in pregnant women and their infants. American Journal of Perinatology, 21(6), 333-339.

46. Silverman, N. S., \& Greif, A. (2001). Influenza vaccination during pregnancy. Patients' and physicians' attitudes. Journal of Reproductive Medicine, 46(11), 989-994.

47. Tuyishime, J. D., De Wals, P., Moutquin, J. M., \& Frost, E. (2003). Influenza-like illness during pregnancy: Results from a study in the eastern townships, Province of Quebec. Journal of Obstetrics and Gynaecology Canada, 25(12), 1020-1025.

48. France, E. K., Smith-Ray, R., McClure, D., Hambidge, S., Xu, S., Yamasaki, K., et al. (2006). Impact of maternal influenza vaccination during pregnancy on the incidence of acute respiratory illness visits among infants. Archives of Pediatrics and Adolescent Medicine, 160(12), 1277-1283.

49. Munoz, F. M., Greisinger, A. J., Wehmanen, O. A., Mouzoon, M. E., Hoyle, J. C., Smith, F. A., et al. (2005). Safety of influenza vaccination during pregnancy. American Journal of Obstetrics and Gynecology, 192(4), 1098-1106.

50. Centre for Health Protection. (2010). Consultation rate of influenza-like illness and number of influenza isolates, 2009. Hong Kong: Author. Accessed 2011 October 12; Available from: http://www.chp.gov.hk/en/data/1/26/44/292/378.html.

51. Centre for Health Protection. (2011). Consultation rate of influenza-like illness and number of influenza isolates, 2010. Hong Kong: Author. Accessed 2011 October 12; Available from: http://www.chp.gov.hk/en/data/1/26/44/292/420.html.
52. Yeager, D. P., Toy, E. C., \& Baker, B., 3rd. (1999). Influenza vaccination in pregnancy. American Journal of Perinatology, 16(6), 283-286.

53. Pool, V., \& Iskander, J. (2006). Safety of influenza vaccination during pregnancy. American Journal of Obstetrics and Gynecology, 194(4), 1200.

54. Omon, E., Damase-Michel, C., Hurault-Delarue, C., Lacroix, I., Montastruc, J. L., Oustric, S., et al. (2011). Non-adjuvant 2009 influenza $\mathrm{A}(\mathrm{H} 1 \mathrm{~N} 1) \mathrm{v}$ vaccine in pregnant women: The results of a French prospective descriptive study. Vaccine, 29(52), 9649-9654.

55. Poehling, K. A., Szilagyi, P. G., Staat, M. A., Snively, B. M., Payne, D. C., Bridges, C. B., et al. (2011). Impact of maternal immunization on influenza hospitalizations in infants. American Journal of Obstetrics and Gynecology, 204(6, Supplement), S141-S148.

56. Zaman, K., Roy, E., Arifeen, S. E., Rahman, M., Raqib, R., Wilson, E., et al. (2008). Effectiveness of maternal influenza immunization in mothers and infants. New England Journal of Medicine, 359(15), 1555-1564.

57. Blanchard-Rohner, G., \& Siegrist, C.-A. (2011). Vaccination during pregnancy to protect infants against influenza: Why and why not? Vaccine, 29(43), 7542-7550.

58. Ahluwalia, I. B., Jamieson, D. J., Rasmussen, S. A., D’Angelo, D., Goodman, D., \& Kim, H. (2010). Correlates of seasonal influenza vaccine coverage among pregnant women in Georgia and Rhode Island. Obstetrics and Gynecology, 116(4), 949-955.

59. Broughton, D. E., Beigi, R. H., Switzer, G. E., Raker, C. A., \& Anderson, B. L. (2009). Obstetric health care workers' attitudes and beliefs regarding influenza vaccination in pregnancy. Obstetrics and Gynecology, 114(5), 981-987.

60. Yudin, M. H., Salaripour, M., \& Sgro, M. D. (2009). Pregnant women's knowledge of influenza and the use and safety of the influenza vaccine during pregnancy. Journal of Obstetrics and Gynaecology Canada, 31(2), 120-125.

61. Lynch, M. M., Mitchell, E. W., Williams, J. L., Brumbaugh, K., Jones-Bell, M., Pinkney, D. E., et al. (in press). Pregnant and recently pregnant women's perceptions about influenza A pandemic (H1N1) 2009: Implications for public health and provider communication. Maternal and Child Health Journal. doi: 10.1007/s10995-011-0865-y.

62. SteelFisher, G. K., Blendon, R. J., Bekheit, M. M., Mitchell, E. W., Williams, J., et al. (2011). Novel pandemic A (H1N1) influenza vaccination among pregnant women: Motivators and barriers. American Journal of Obstetrics and Gynecology, 204(6, Supplement), S116-S123.

63. Chi-fai, C. (2010). Third woman suffers stillbirth after having swine flu vaccination. South China Morning Post.

64. Ng, Y.-h. (2010). Woman loses baby; flu jab not to blame, doctors say. South China Morning Post.

65. Ng, Y.-h. (2010). 4 women lost babies after shots, but vaccine not cause, says official. South China Morning Post.

66. Benitez, M. A. (2010). Swine flu jab takes hit as man, 91, falls ill. The Standard.

67. Ng, Y.-h. (2010). Pregnant women told to continue flu shots. South China Morning Post.

68. Chor, J. S., Ngai, K. L., Goggins, W. B., Wong, M. C., Wong, S. Y., Lee, N., et al. (2009). Willingness of Hong Kong healthcare workers to accept pre-pandemic influenza vaccination at different WHO alert levels: Two questionnaire surveys. BMJ, 339, b3391.

69. Wong, S. Y., Wong, E. L., Chor, J., Kung, K., Chan, P. K., Wong, C., et al. (2010). Willingness to accept H1N1 pandemic influenza vaccine: a cross-sectional study of Hong Kong community nurses. BMC Infectious Diseases, 10, 316.

70. Esposito, S., Tremolati, E., Bellasio, M., Chiarelli, G., Marchisio, P., Tiso, B., et al. (2007). Attitudes and knowledge regarding 
influenza vaccination among hospital health workers caring for women and children. Vaccine, 25(29), 5283-5289.

71. Mersereau, P. W., Layton, C. M., Smith, L. R., Kendrick, J. S., Mitchell, E. W., Amoozegar, J. B., et al. (in press). Prenatal care providers and influenza prevention and treatment: Lessons from the field. Maternal and Child Health Journal. doi:10.1007/s10995011-0753-5.

72. Yudin, M. H., Salaripour, M., \& Sgro, M. D. (2010). Acceptability and feasibility of seasonal influenza vaccine administration in an antenatal clinic setting. Journal of Obstetrics and Gynaecology Canada, 32(8), 745-748.

73. Rehmet, S., Ammon, A., Pfaff, G., Bocter, N., \& Petersen, L. R. (2002). Cross-sectional study on influenza vaccination, Germany, 1999-2000. Emerging Infectious Diseases, 8(12), 1442-1447.
74. Tucker Edmonds, B., Coleman, J., Armstrong, K., \& Shea, J. (2011). Risk perceptions, worry, or distrust: What drives pregnant women's decisions to accept the H1N1 vaccine? Maternal Child Health Journal, 15, 1203-1209.

75. Kwon, Y., Cho, H.-Y., Lee, Y.-K., Bae, G.-R., \& Lee, S.-G. (2010). Relationship between intention of novel influenza A (H1N1) vaccination and vaccination coverage rate. Vaccine, 29(2), 161-165.

76. Nemes, S., Jonasson, J. M., Genell, A., \& Steineck, G. (2009). Bias in odds ratios by logistic regression modelling and sample size. BMC Medical Research Methodology, 9(56). 